\title{
Medical oncology management of advanced hepatocellular carcinoma 2019: a reality check
}

\author{
Amy Lee ${ }^{1}$, Fa-Chyi Lee $(\varangle)^{2}$ \\ ${ }^{I}$ Department of Biology, University of California San Diego, San Diego, CA 92093, USA; ${ }^{2}$ Division of Hematology/Oncology, Department of \\ Internal Medicine, University of California Irvine, Orange, CA 92868, USA
}

(C) The Author(s) 2019. This article is published with open access at link.springer.com and journal.hep.com.cn

\begin{abstract}
In terms of global cancer-related deaths, hepatocellular carcinoma (HCC) has the fourth highest mortality rate. Up until 2017, treatment of advanced HCC was largely limited to sorafenib, an oral tyrosine kinase inhibitor, with little to no success in the development of alternative treatment options. However, in the past two years, there has been an unprecedented increase in both the number and type of treatment options available for HCC. As of 2019, the US FDA has approved four oral tyrosine kinase inhibitors, two immune checkpoint inhibitors, and one anti-angiogenesis antibody for the treatment of HCC. Even with this new variety, systemic treatment of advanced HCC remains largely unsatisfactory, and the median survival rate stands at approximately one year. The expected breakthrough of using immune checkpoint inhibitors in advanced HCC did not materialize in 2019. The use of immune checkpoint inhibitors in conjunction with oral tyrosine kinase inhibitors or antiangiogenesis medications is the current clinical research trend, the results of which are eagerly anticipated. Despite limited progress in survival, $\mathrm{HCC}$ research is currently experiencing a period of growth and innovation, and there is hope for significant advances in the treatment of advanced $\mathrm{HCC}$ as the field continues to develop.
\end{abstract}

Keywords hepatocellular carcinoma; tyrosine kinase inhibitor; check point inhibitor; anti-angiogenesis

\section{Introduction}

Hepatocellular carcinoma (HCC) stands as the fourth leading cancerous cause of death in the world, and therefore remains a global issue. Potentially curative treatments, which include surgical resection and liver transplantation, are limited to patients with early detected HCC. Late diagnosis of HCC is much more common, and severely limits available treatment options to palliative systemic treatment. As a result, treatment of $\mathrm{HCC}$ has been historically unsatisfactory, with a median survival rate of approximately 1 year. However, advances in systemic treatment options for HCC are currently experiencing a rapid growth: in the past two decades and predominantly in the past two years, the available treatment options for advanced HCC have expanded from a single cytotoxic drug to four oral kinase inhibitors, two immune checkpoint inhibitors and one anti-angiogenesis monoclonal antibody

Received July 21, 2019; accepted October 12, 2019

Correspondence: Fa-Chyi Lee, fachyil@uci.edu
(Fig. 1). There is currently no unified mechanism to explain why any of the oral kinase inhibitors are effective treatments for HCC, and there is a lack of identifiable marker(s) to select HCC patients for immune checkpoint inhibitors. While single agent immunotherapy has resulted in only comparable overall survival to the current standard treatment, preliminary data from the use of immunotherapy agents used in combination with either oral kinase inhibitors or anti-angiogenesis medications shows promising response rates, and results on using this combination treatment are eagerly awaited. Cytotoxic agents are used much less frequently for the treatment of HCC, but the new direction is moving toward use in combination with tyrosine kinase inhibitors or immune checkpoint inhibitors.

This review will chronicle the evolution of treatments in HCC, with a final outline of the current recommended treatment algorithm. Despite the recent influx of available treatment options for the treating oncologist to consider for $\mathrm{HCC}$, the progress in systemic treatment of $\mathrm{HCC}$ has been unsatisfactory. However, in this period of global cooperation and high-throughput innovation, there is hope for major breakthroughs in the treatment of HCC. 


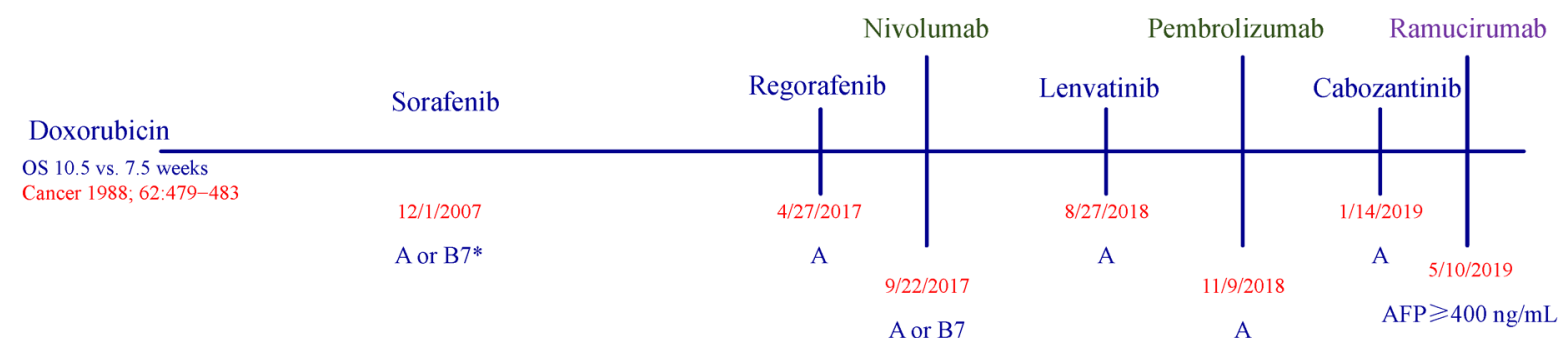

Fig. 1 Timeline of the US FDA approval for HCC treatments. The approval of sorafenib was followed by a decade of stagnation until several treatment options were approved from 2017 to 2019. * indicates Child-Pugh Classification.

\section{Doxorubicin}

Historically, doxorubicin has been the main treatment option available for medical oncology for decades. A 1998 randomized clinical trial involving a total of 46 patients compared the best supportive care to single agent doxorubicin at doses of $60-75 \mathrm{mg} / \mathrm{m}^{2}$, administered once every three weeks [1]. The median survival was 10.6 weeks for the doxorubicin group and 7.5 weeks for the supportive group, $P=0.036$. Side effects such as neutropenia and cardiotoxicity, make routine use of doxorubicin difficult in patients with advanced HCC. However, doxorubicin became the comparator arm for subsequent trials. A group of researchers from Hong Kong, China conducted a multicenter phase 2 trial with 54 patients comparing single agent nolatrexed dihydrochloride to doxorubicin. The nolatrexed was given at $725 \mathrm{mg} / \mathrm{m}^{2} /$ day by continuous infusion and doxorubicin was delivered at $60 \mathrm{mg} / \mathrm{m}^{2}$ via rapid intravenous injection once every three weeks [2]. No objective response was observed in either arm, and both drugs are considered to be minimally active in HCC. Another phase 3 trial published in 2007 involving 445 patients randomized to either doxorubicin or nolatrexed showed increased survival with doxorubicin (32.3 weeks versus 22.3 weeks, $P=0.0068$ ) [3]. As with the Hong Kong phase 2 trial, both doxorubicin and nolatrexed were considered minimally active in HCC.

\section{Liposomal doxorubicin}

The US FDA approved the use of liposomal doxorubicin, a membrane-bound version of doxorubicin with decreased cardiotoxicity, in women with ovarian cancer in June 1999. Since then, its use has expanded into treatment of ASIDKaposi's sarcoma, multiple myeloma breast cancer, lymphoma, and HCC. An initial phase 2 trial using 30 $\mathrm{mg} / \mathrm{m}^{2}$ once every three weeks in 16 patients did not show an objective response with median survival time only 140 days (126-154 days) [4]. However, another pilot study showed a much higher clinical benefit in $50 \%$ of the 17 treated patients at dose of $40 \mathrm{mg} / \mathrm{m}^{2}$ once every 4 weeks
[5]. No other trial reported such a high clinical benefit rate using single agent liposomal doxorubicin in HCC. A phase 2 trial with 40 patients used an escalating dosage scheme starting from $30 \mathrm{mg}$ and increasing to $45 \mathrm{mg} / \mathrm{m}^{2}$ once every 3 weeks and reported a $10 \%$ response rate; these results are more similar to the results seen in clinical experiences [6].

Despite the low response rate and very unimpressive survival benefits, doxorubicin and liposomal doxorubicin continued to be the main cytotoxic drugs used for systemic treatment of HCC until 2007.

\section{Sorafenib}

The US FDA approved sorafenib, a multi-target tyrosine kinase inhibitor (TKI), on December 20, 2005 for use in patients with advanced renal cell carcinoma. The exact mechanism of how sorafenib regulates renal cell carcinoma is unknown, as it inhibits multiple kinases involved in cell proliferation and angiogenesis [7]. A study conducted in 2006 found that in hepatocellular PLC/PRF/5 xenograft models, sorafenib was shown to induce tumor cell apoptosis [8]. Additionally, a phase 1 trial recruited 69 patients with refractory solid tumors across a panel of cancers and found that among the 45 patients available for efficacy evaluation, the only patient to show a partial response had HCC [9]. Because of this, a phase 2 trial that recruited 137 patients with $\mathrm{HCC}$ was conducted soon after. All patients had no prior treatment and were classified as Child-Pugh A or B. Based on the independent assessment, only three patients $(2.2 \%)$ achieved a partial response. The overall survival was 9.2 months with median time to progression at 4.2 months [10]. It was noted that there was an increase in tumor necrosis from the baseline average of $9.8 \%$ to $27 \%$ among the 11 patients that were assessed specifically for tumor necrosis. As with renal cell carcinoma, the mechanism through which sorafenib affects HCC is unknown. Multiple kinases are potential targets of sorafenib, but no specific kinase inhibition or mechanism has been identified as the main effector for sorafenib in HCC.

A multicenter, phase 3, double-blind, placebo-controlled 
trial (SHARP) was conducted following the promising results of the phase 1 and 2 trials. The study was stopped after the second planned interim analysis, at which point 321 deaths had occurred. Median survival was 10.7 months in the sorafenib group and 7.9 months in the placebo group, $P<0.001$. Similar to the earlier phase 2 trial, the radiographic response rate was low at $2 \%$. However, the median time to radiological progression was significantly longer in the sorafenib group than the placebo group (5.5 months versus 2.8 months, $P<0.001)$ [11]. This data led to US FDA approval of sorafenib as front-line therapy in Child-Pugh Class A patients with HCC on Dec $1,2007$.

While the SHARP trial recruited patients from Europe, North and South America, and Australasia, a separate Asia-Pacific trial was being conducted parallel with the SHARP trial in Chinese Mainland, South Korea and Taiwan, China. The total number of patients recruited into the Asia-Pacific trial was smaller with 271 patients, compared to the SHARP trial with 602 patients. Both trials reported similar side effects of diarrhea and hand-foot syndrome in the sorafenib group. However, the AsiaPacific trial reported shorter median survival results in both the sorafenib and placebo groups (6.5 and 4.2 months, $P=$ 0.014) [12] compared to the SHARP trial. Although the randomization was 1:1 for the SHARP trial and 2:1 for the Asia-Pacific trial, these differences in trial design are not sufficient to explain the discrepancies in median survival between the two trials. The cause behind the differing median survival rate between the two trials remains unknown.

\section{Sorafenib and doxorubicin}

Despite unimpressive clinical results, sorafenib broke the monotony of systemic cytotoxic treatment of $\mathrm{HCC}$ via doxorubicin and lysosomal doxorubicin; it came as no surprise that studies utilizing a combination of doxorubicin and sorafenib were conducted next. In a dose-finding phase 1 trial involving 34 patients with various refractory solid tumors, 4 of the 15 patients that achieved disease stabilization for $\geqslant 12$ weeks were HCC patients [13]. Doses of sorafenib at $400 \mathrm{mg}$ BID daily with doxorubicin at $60 \mathrm{mg} / \mathrm{m}^{2}$ once every three weeks were recommended for further study. The same group of researchers extended their phase 1 trial using a treatment scheme in which a combination of sorafenib with doxorubicin was administered for 6 cycles, followed by single agent sorafenib for at least 3 more months. Neutropenia became the dominant side effect in $61 \%$ of participants, as expected from treatment with doxorubicin. The disease control rate among the 16 evaluable patients showed promise at $69 \%$ [14]. However, the results of a randomized trial using sorafenib plus doxorubicin versus sorafenib single agent were disappointingly negative, and the trial was discontinued after a planned interim analysis showed that the futility boundary was not crossed. A median overall survival rate of 9.3 months was observed in the combination arm versus 10.5 months in the single agent sorafenib arm [15]. Side effects in the combination arm were more severe, especially for hematologic adverse events, and no progression-free survival benefit was observed.

Epidermal growth factor receptor (EGFR) pathway activation is part of the pathogenesis of HCC and could negatively affect the responsiveness to sorafenib [16]. A phase 3 randomized, double-blind, placebo-controlled trial of sorafenib with or without erlotinib, an EGFR inhibitor, was conducted (SEARCH). However, clinically significant benefits were observed in neither overall survival nor median time to progression [17].

\section{7-2017}

The exact mechanism through which sorafenib provides survival benefits in patients with advanced HCC remains unknown. Because sorafenib is known to inhibit multiple tyrosine kinases, it was speculated that inhibition through multiple targets may be necessary to treat patients with advanced HCC. Along this line of reasoning, several other multi-target tyrosine kinase inhibitors (TKIs) were tested in HCC patients.

Sunitinib, similar to sorafenib, was initially approved by the US FDA for treatment of advanced renal cell carcinoma. Like sorafenib, sunitinib targets multiple kinases and is a strong inhibitor of vascular endothelial growth factor receptor (VEGFR) [18]. However, an open phase 3 trial with direct comparison of sunitinib to sorafenib showed that survival time was similar in Asian and hepatitis B infected individuals with HCC (7.6 and 8 months, respectively). A surprising finding was a shorter survival duration with sunitinib than with sorafenib in hepatitis $\mathrm{C}$ infected individuals with $\mathrm{HCC}$ (9.2 versus 17.6 months). Side effects were more frequently reported with sunitinib than sorafenib, especially for thrombocytopenia and neutropenia [19].

Brivanib alaninate (BMS-582664) has a dual activity in inhibiting VEGF and fibroblast growth factor receptor (FGFR) [20]. Despite promising basic science and xerograph data, brivanib was no better than sorafenib as a first line treatment for HCC [21] and had non-significant benefits as a second line treatment compared to best supportive care after intolerance to or progression on sorafenib [22].

It was a decade of stagnation for the treatment of advanced HCC, not for lack of trying but for lack of success. 


\section{Beyond sorafenib}

After the lull in HCC treatment progression from 2007 to 2017, three additional multi-target TKIs have been approved for treatment of HCC in less than two years. Like sorafenib, these TKIs were not developed specifically for the treatment of HCC but were initially US FDA approved for the treatment of other cancers (Table 1) before they were granted use in HCC.

Regorafenib was initially approved by the US FDA for colorectal cancer after progression as a third line option in 2012. Regorafenib is a multi-kinase inhibitor but its mechanism in colorectal cancer was never clearly elucidated [23]. It is thought to affect mainly through inhibition of several angiogenic receptor tyrosine kinases [24]. The US FDA approved regorafenib as a second line treatment for HCC after progression on sorafenib in April 27, 2017 based on the results from a randomized phase 3 trial (RESORCE). The trial randomized 573 patients with Child-Pugh A in a 2:1 ratio of regorafenib versus placebo. The median survival was 10.6 months versus 7.8 months, $P<0.0001$ [25].

Lenvatinib is a multi-target TKI that targets VEGF receptors 1-3 and FGFRs 1-4 [26]. A phase 2 trial conducted in Japan and South Korea suggested a high response rate $(37 \%)$ and a promising median overall survival duration of 18.7 months in 46 patients [27]. This lead to a non-inferior trial with direct comparison to sorafenib as the first line treatment for HCC [28]. The median overall survival was 13.6 months versus 12.3 months for the lenvatinib and sorafenib groups, respectively, and the US FDA approved lenvatinib on August 16, 2018 as an alternative to sorafenib for the front-line treatment of advanced HCC. Many oncologists move to use lenvatinib as the preferred front-line therapy over sorafenib in treating patients with HCC, mainly based on its higher response rate $(24.1 \%$ vs $9.2 \%)$ and more favorable toxicity profile (Table 2).

Cabozantinib, like the others, is also a multi-target TKI [29]. A randomized phase 2 trial compared to placebo in 41 patients after progression on at least one line of therapy showed a promising overall survival of 11.5 months [30]. This lead to a phase 3 trial comparing carbozantinib to placebo after progression in 707 patients. The median survival was 10.2 months in the cabozantinib group versus 8 months in the placebo group, $P=0.005$ [31]. The US FDA approved cabozantinib as a second line treatment for HCC on January 14, 2019.

Table 2 summarizes the clinical efficacy and toxicity of the four oral TKIs in treatment of HCC.

As of 2019, there are four oral TKIs for the treatment of HCC (Table 2). Sorafenib and lenvatinib are typically used

Table 1 US FDA approval dates for use of the four oral TKIs in various cancers

\begin{tabular}{|c|c|c|c|c|c|}
\hline & $\mathrm{HCC}$ & Kidney cancer & Thyroid cancer & Colon & GIST \\
\hline Sorafenib & $12 / 1 / 2007$ & $12 / 20 / 2005$ & $12 / 22 / 2013$ & - & $\begin{array}{l}\text { NCCN guideline, off label } \\
\text { use }\end{array}$ \\
\hline Regorafenib & $4 / 27 / 2017$ & - & - & $8 / 30 / 2012$ & $2 / 25 / 2013$ \\
\hline Lenvatinib & $8 / 16 / 2018$ & $3 / 13 / 2016$ & $2 / 13 / 2015$ & - & - \\
\hline Cabozantinib & $1 / 14 / 2019$ & $4 / 26 / 2017$ & - & - & - \\
\hline
\end{tabular}

Approval dates for sorafenib, regorafenib, lenvatinib and cabozantinib for use in $\mathrm{HCC}$, kidney cancer, thyroid cancer, colon cancer and gastrointestinal stromal tumors (GIST).

Table 2 Clinical efficacy and toxicity of the four oral TKIs in treatment for HCC

\begin{tabular}{|c|c|c|c|c|c|c|c|c|c|c|}
\hline & \multirow[b]{2}{*}{ TKI } & \multirow{2}{*}{$\begin{array}{l}\text { Complete } \\
\text { response } \\
\text { rate }\end{array}$} & \multirow{2}{*}{$\begin{array}{l}\text { Partial } \\
\text { response } \\
\text { rate }\end{array}$} & \multirow{2}{*}{$\begin{array}{l}\text { Median time } \\
\text { to progression } \\
\text { (month) }\end{array}$} & \multirow{2}{*}{$\begin{array}{l}\text { Overall } \\
\text { survival } \\
\text { (month) }\end{array}$} & \multicolumn{4}{|c|}{ Top four reported side effects } & \multirow[b]{2}{*}{ Reference } \\
\hline & & & & & & 1 & 2 & 3 & 4 & \\
\hline \multirow[t]{2}{*}{ First line } & Sorafenib & $<1 \%$ & $9 \%$ & 3.7 & 12.3 & $\begin{array}{l}\text { Hand-foot } \\
\text { reaction } \\
52 \%\end{array}$ & $\begin{array}{l}\text { Diarrhea } \\
46 \%\end{array}$ & $\begin{array}{l}\text { Hypertension } \\
34 \%\end{array}$ & $\begin{array}{l}\text { Decreased } \\
\text { appetite } \\
27 \%\end{array}$ & {$[28]$} \\
\hline & Lenvatinib & $1 \%$ & $23 \%$ & 8.9 & 13.6 & $\begin{array}{l}\text { Hypertension } \\
42 \%\end{array}$ & $\begin{array}{l}\text { Diarrhea } \\
39 \%\end{array}$ & $\begin{array}{l}\text { Decreased } \\
\text { appetite } 34 \%\end{array}$ & $\begin{array}{l}\text { Weight loss } \\
31 \%\end{array}$ & [28] \\
\hline \multirow[t]{2}{*}{ Second line } & Regorafenib & $1 \%$ & $11 \%$ & 3.1 & 10.6 & $\begin{array}{l}\text { Hypertension } \\
15 \%\end{array}$ & $\begin{array}{l}\text { Hand-foot } \\
\text { reaction } 13 \%\end{array}$ & Fatigue $9 \%$ & Diarrhea 3\% & {$[25]$} \\
\hline & Cabozantinib & Not reported & $4 \%$ & 5.2 & 10.2 & $\begin{array}{l}\text { Hand-foot } \\
\text { reaction } 17 \%\end{array}$ & $\begin{array}{l}\text { Hypertension } \\
16 \%\end{array}$ & $\begin{array}{c}\text { Increased liver } \\
\text { enzyme } 12 \%\end{array}$ & Fatigue $10 \%$ & {$[31]$} \\
\hline
\end{tabular}

Complete and partial response rates, median time to progression, median overall survival and top four reported side effects of sorafenib, lenvatinib, regorfenib and cabozantinib. 
as front-line treatment. Regorafenib and cabozantinib are reserved for second or subsequent line settings.

All four of these oral TKIs affect many targets, leading to diverse outcomes in various cancer types. A complete list of all the proposed targets for the four TKIs is beyond the scope of this review. Table 3 lists the proposed main targets for each medication.

\section{Anti-angiogenesis medications}

Because all four US FDA approved oral TKIs target VEGFR, it is suspected that TKIs are able to confer HCC survival benefits through anti-angiogenesis effects. If this truly were the case, one would expect that medications with dominant anti-angiogenesis effects would be at least equal, if not better than oral kinase inhibitors in controlling HCC. This line of thinking led to several trials involving the use of anti-angiogenesis medications for treatment of HCC. There are three US FDA approved medications that fit the criteria of being primarily anti-angiogenic: bevacizumab, aflibercept, and ramucirumab. All three are monoclonal antibodies.

Bevacizumab was initially approved by the US FDA on February 26, 2004 for the treatment of metastatic colorectal cancer. The first pure angiogenesis inhibitor in the US, the main target of bevacizumab is circulating VEGF-A [32]. Several trials using bevacizumab alone or in combination with other agents to treat $\mathrm{HCC}$ have shown overall survival durations ranging between 5.9 to 13.7 months. A comprehensive review article published in 2012 concluded that bevacizumab may be comparable to sorafenib for the treatment of HCC [33]. A planned phase $1 / 2$ randomized trial of sorafenib with or without bevacizumab was terminated early due to low efficacy, excessive toxicity and slow enrollment [34]. As such, there is no data directly comparing the effectiveness of bevacizumab to that of sorafenib in treatment of HCC.

Aflibercept binds circulating VEGF-A/B, as well as placental growth factor. It was approved by the US FDA in August 3, 2012 as second line, combination treatment with irinotecan-based regimen for metastatic colorectal cancer. Currently, aflibercept has demonstrated antitumor activity in HCC mouse models only [35].
Lastly, ramucirumab is a recombinant IgG1 monoclonal antibody that binds to the extracellular domain of VEGFR2 with high affinity [36]. A randomized trial that recruited patients with $\mathrm{HCC}$ who were on second line treatments following progression on sorafenib (REACH) showed numerically better survival than the placebo group but the $P$ value was not significant on the intent to treat analysis (9.2 versus 7.6 months, $P=0.14, N=565$ ) [37]. Subgroup analysis hinted that patients with a high baseline $\alpha$-fetoprotein concentration of $\geqslant 400 \mathrm{ng} / \mathrm{mL}$ seemed to derive a survival benefit ( 7.8 versus 4.2 months, $P=$ $0.006)$. This prompted a second randomized trial recruiting HCC patients with a high $\alpha$-fetoprotein concentration, which confirmed a survival benefit in this particular subset of patients ( 8.5 versus 7.3 months, $P=0.0199$ ) [38]. The US FDA granted marketing approval of ramucirumab on May 10, 2019 as a second line treatment for advanced HCC patients with a high $\alpha$-fetoprotein concentration.

There is a lack of front-line direct comparison trials of oral kinase inhibitors to the three anti-VEGF monoclonal antibodies, but the available data do not point to drastic improvement in all end points, especially survival duration, with any of the pure anti-angiogenesis medications. As such, it casts doubt on the theory of anti-angiogenesis being the major mechanism of action against $\mathrm{HCC}$ with the US FDA-approved TKIs. Therefore, the mechanism through which the four US FDA-approved TKIs confer survival benefits remains unknown and remains a barrier blocking improvement in $\mathrm{HCC}$ treatment.

\section{Precision medicine in HCC}

The promise of the precision medicine is to identify and target driver mutation(s) in hopes of achieving long-term disease control. Lung cancer with EGFR mutations, ALK fusion proteins, and BRAF mutations in melanoma are some of the most recognizable successes of treatment of solid tumors using precision medicine.

Gene mutation frequency analysis in HCC based on 1289 cases identified many common mutations but most of the mutations do not currently have drugs to target them [39]. However, the RTK-RAS-PI3K signaling pathway is known to be involved in pathogenesis of HCC and can be

Table 3 Main targets of the four US FDA-approved oral TKIs in HCC

\begin{tabular}{lllllllll}
\hline & VEGFR & FGFR & PDGFR & C-kit & Raf & RET & C-Met & FLT3 \\
\hline Sorafenib & $1-3$ & - & $\beta$ & + & C $>$ B & + & - & + \\
Regorafenib & 2 & - & - & $\alpha$ & + & - & - & - \\
Lenvatinib & $1-3$ & $1-4$ & - & - & - & + & - & - \\
Cabozantinib & 2 & - & - & - & - & + & - \\
\hline
\end{tabular}

All four TKIs target one or more VEGFR receptors. Only lenvatinib targets FGFR, while sorafenib and lenvatinib target PDGFR- $\beta$ and PDGFR- $\alpha$, respectively. All TKIs target C-kit, with the excepetion of cabozantinib. Sorafenib targets Raf C more than Raf B. Regorafenib is the only TKI of the four that does not target RET. Cabozantinib is the only TKI that targets C-Met, while sorafenib is the only TKI that targets FLT3. 
targeted with a MET inhibitor. For example, cabozantinib is considered to have potent MET inhibitory activity, and is approved for second line treatment of HCC (Table 3). However, because cabozantinib targets multiple kinases, it is still uncertain if MET inhibition is the main mechanism through which cabozatinib improved survival in patients with HCC. Tivantinib, another potent MET inhibitor was found to result in a longer median time to progression compared to placebo in a second line phase 2 randomized trial after progression on sorafenib, especially among patients with MET-high HCC (defined as $\geqslant 2+$ in 50\% of tumor cells by immunohistochemistry staining) [40]. This prompted a follow-up phase 3 trial aimed specifically at MET-high HCC patients who progressed on sorafenib. The promising phase 2 data was not sustained with the phase 3 trial, with median overall survival of 8.4 months in the tivantinib group versus 9.1 months in the placebo group [41]. It is sufficient to conclude that the promise of precision medicine has not materialized in the treatment of advanced HCC. Further molecular characterization of HCC into several subclasses has not proven to be clinical useful $[42,43]$. A lack of true understanding of how various mutations initiate and propagate the progression of HCC coupled with an inability to identify which driver mutation (s) to target is the most likely explanation for the limited progress in systemic treatment of HCC.

\section{Immune-check point inhibitors}

The overall survival in patients with advanced $\mathrm{HCC}$ continues to hover around one year even with the increase in available treatment options. Each oral medication is accompanied by its unique toxicity profile and is only beneficial for patients with well-preserved liver function, mainly Child-Pugh A patients.

The medical oncology community buzzed with excitement when second line treatment data using nivolumab (an anti-PD-1 monoclonal antibody) in advanced HCC was published in 2017 (CheckMate-040) [44]. The response rate of $20 \%$ among the patients treated with $3 \mathrm{mg} / \mathrm{kg}$ of nivolumab was the highest ever reported with a single agent in the treatment of HCC. This encouraging result led to US FDA approval of nivolumab on September 22, 2017 for use as a second line treatment for patients with HCC.

It was followed by a phase 3 randomized trial of sorafenib versus nivolumab (CheckMate-459). The results were highly anticipated to change the treatment landscape of HCC. The planned results presentation was delayed several times in 2018, at both the American Society of Clinical Oncology (ASCO) annual meeting and the European Society of Medical Oncology (ESMO) meeting. Eventually, the company released an announcement on June 24, 2019 with the very disappointing news that the study had resulted in no overall survival benefit (the primary end point of the trial). The full data has not been published.

Pembrolizumab, another anti-PD-1 check-point inhibitor, was similarly studied in a phase II (KEYNOTE-224) single arm setting in patients progressed on sorafenib. Encouraging results of a 17\% response rate were reported, with one patient achieving complete remission and an additional $44 \%$ with stable disease [45]. These results lead to the US FDA approval of pembrolizumab on November 9, 2018 for the treatment of HCC after progression on sorafenib. This was followed by a randomized trial (KEYNOTE-240) comparing pembrolizumab to placebo in a second line setting. Although the high response rate was maintained in this randomized trial $(16.9 \%)$, the coprimary end points of progression-free survival $(P=$ $0.0209)$ and overall survival $(P=0.0238)$ did not meet prespecified significant level [46].

Before the results of CheckMate-459 and KEYNOTE240 were available, many trials incorporated immunecheck point inhibitors with a second agent in hopes of improving overall outcome. One example is the combination of Atezolizumab (an anti-PD-L1 inhibitor) and bevacizumab. The initial presentation at the ESMO 2018 meeting showed an impressive response rate of $61 \%$ among the 23 evaluable patients [47]. No further update on this trial was presented in the ASCO annual meeting in June 2019. From China, a dose escalation and expansion trial using SHR-1210 (an anti-PD-1 inhibitor) in conjunction with Apatinib (an oral multi-kinase inhibitor) was noted to have a high response rate of $50 \%$ among the 16 evaluable patients with HCC [48].

The ongoing first line randomized trials of atezolizumab + bevacizumab versus sorafenib and the similarly designed global randomized trial of SHR-1210 + Apatinib versus sorafenib will hopefully point to the future direction on how immunotherapy should be incorporated into the treatment of HCC. It appears that the trend is to combine an immune checkpoint inhibitor with either TKIs, chemotherapy, or mammalian target of rapamycin inhibitor. How best to sequence the administration of these medications and whether optimal sequencing may result in longer survival remains unclear. A small retrospective analysis noted that treatment with TKIs then immunotherapy then TKIs appears to be safe, and some patients did derive added benefits, but the data are too preliminary to draw any conclusions [49]. An excellent review article published in 2019 listed all the current ongoing trials involving checkpoint inhibitors; many are utilizing a combination approach [50]. We are eagerly awaiting these trial results to determine if any particular combination proves to be more effective than others.

MD Anderson Cancer Center reviewed its institutional data on recipients $(N=39)$ of various solid organ allograft transplants (kidney, liver, and heart) who developed malignant diseases (melanoma, lung cancer, HCC, cuta- 
neous squamous cell carcinoma) then received checkpoint inhibitors and found high rates of graft loss $(81 \%)$ and a high death rate $(46 \%)$ [51]. Therefore, patients with recurrent $\mathrm{HCC}$ after liver transplant should receive immune checkpoint inhibitor treatment with the upmost caution at the risk of rapid organ rejection, as published in multiple case reports [52]. However, there is also a potential to harness the power of checkpoint inhibitor(s) alone or in combination with other agent(s) to amplify the antitumor effects [53]. There is lack of data on whether immunotherapy use prior to liver transplant will affect graft survival in patients with HCC.

\section{Advances in systemic cytotoxic chemotherapy}

Patients with HCC are surviving longer with the many oral treatment options, some with the additional benefit of immunotherapy treatment. However, these improvements are small steps, not leaps forward. For that reason, the systemic cytotoxic chemotherapy regimens continue to be an option for select individuals. Oxaliplatin in combination with 5-FU infusion (FOLFOX) was directly compared to doxorubicin and showed a trend toward a better survival (6.4 vs. 4.97 months, $P=0.07$ ) [54]. A phase 2 trial that evaluated the combination of Oxaliplatin and oral S-1 showed a promising median survival time of 10.3 months [55]. Several ongoing trials combing cytotoxic agent(s) with oral TKI(s) will also guide future developments in treatment options for $\mathrm{HCC}$.

As outlined below on the proposed current treatment scheme in patients with advanced/metastatic HCC, cytotoxic chemotherapy is no longer the primary front-line treatment in clinical practice. Although the National Comprehensive Cancer Network (NCCN) guidelines list cytotoxic chemotherapy as a front-line option, chemotherapy with cytotoxic drugs will only be considered after progression on several lines of treatment in most clinical settings (Fig. 2). However, after several lines of treatment, the patient's overall conditions have likely declined significantly, even among patients with good hepatic reserve initially, eliminating treatment with cytotoxic chemotherapy as an option. This further limits the potential use of cytotoxic drugs in patients with HCC.

\section{Anti-viral therapy}

One major obstacle in treating patients with $\mathrm{HCC}$ is that many patients have poor hepatic reserve and are not able to tolerate oral kinase inhibitors and systematic cytotoxic chemotherapy. As shown in Fig. 1, all current US FDA approved medications are approved for patients with adequate hepatic reserve (Child-Pugh Class A or up to B7). The US FDA approved the first non-interferon, oral treatment (ledipasvir/sofosbuvir) with a high viral remission rate for the treatment of hepatitis $\mathrm{C}$ infection in October 2014, which generated great excitement among the medical oncology community. There were two ideas to

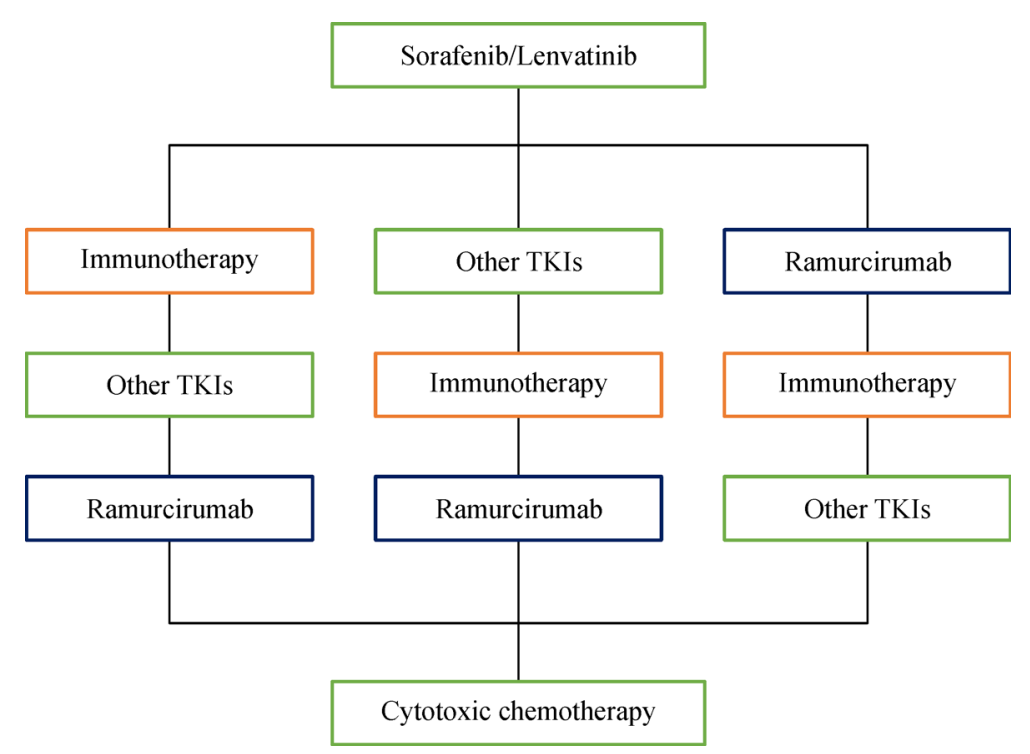

Fig. 2 Current treatment scheme for patients with advanced/metastatic HCC. Sorafenib/lenvatinib has replaced doxorubicin as the standard front-line treatment. Nivolumab or pembrolizumab are the most commonly used immunotherapy treatments. Other TKIs include regorafenib, cabozantinib or lenvantinib if lenvantinib was not used as the front-line treatment. Use of Ramucirumab is limited to patients with AFP $\geqslant 400 \mathrm{ng} / \mathrm{mL}$. Cytotoxic chemotherapy is listed as an "Other recommended" first-line treatment option on the NCCN Guidelines. 
incorporate treatment of Hep $\mathrm{C}$ into the overall management of patients with HCC. The first thought was to deploy the anti-Hep $\mathrm{C}$ treatment as secondary prevention after initial treatment of HCC. The second thought was to use anti-Hep C treatment as the primary approach in patients with poor hepatic reserve who are not able to tolerate either oral TKIs or any chemotherapy. The hope was that by treating the active viral infection, the progression of the HCC could be slowed or hepatic function could be improved for better quality of life.

However, two publications back to back on the same issue of Journal of Hepatology in October 2016 sounded the alarm on possible early recurrence with anti-Hep C treatment in patients with treated HCC [56,57]. Subsequent retrospective review of 1897 patients from Japan did not find differences in de novo occurrence or recurrence of HCC among patients treated with interferon-based $(N=$ 1142) versus interferon-free regimen $(N=755)$ [58]. A retrospective cohort study from 31 centers in the US and Canada that included 793 patients with treated HCC noted that direct acting antiviral use did not affect the recurrence rate or subsequent response to treatment of the recurrent HCC (304 treated versus 489 untreated) [59]. Articles that reviewed published studies also failed to sustain the initial observation of early recurrence of HCC with interferonfree anti-Hep $C$ treatment $[60,61]$. Of note, these articles were all observational and retrospective analyses. The opportunity is open for a prospective trial to confirm if treating chronic hepatitis $\mathrm{C}$ infection is safe for patients with HCC. Currently, patients starting direct-acting antiviral therapy for hepatitis $\mathrm{C}$ require close monitoring for HCC.

Treatment of hepatitis B in patients with known HCC is much less controversial. It is generally considered safe and is recommended to administer with concurrent treatment for HCC $[62,63]$.

\section{Conclusions}

Treatment of HCC has advanced from very limited chemotherapy options to four oral TKIs, two immune checkpoint inhibitors and one anti-angiogenesis inhibitor. Superficially, it appears that treatment of HCC has progressed; however, despite the increased number of treatment options, the overall outlook for patients with HCC remains very poor, with median survival around only one year. Additionally, promising data from the use of immunotherapy in conjunction with oral TKIs/anti-angiogenesis medications is still developing; whether specific sequences of treatment can confer additional survival benefits is still unclear.

Patients with HCC should ideally be managed by a multi-discipline team that includes gastroenterologist, surgeon, radiation oncologist, intervention radiologist, and medical oncologist. How and when to combine TKIs and checkpoint inhibitors with other treatment modalities are areas of active research. Laparoscopic surgery is an option for selected patients with HCC. Interventional radiology can provide embolization, chemoembolization, radioembolization, hepatic arterial infusion of chemotherapy agent and several ablative methods. Advances in treatment planning and delivery, such as stereotactic body radiotherapy and proton beam, that deliver adequate treatment dose to tumors while sparing normal liver tissue makes radiation oncology an active participant in managing HCC more than palliative pain control of bone metastases.

Although the survival improvement in patients with HCC has been limited during the past decades from the medical oncology standpoint, it is also an exciting time with the rapid development of new treatment options that were not available before. We have learned from both the successful and the failed trials to redirect our approaches: in less than 3 years we learned that a single agent checkpoint inhibitor is no better than sorafenib for first line treatment and no better than best supportive care after progressing on sorafenib for patients with HCC, but yields promising results when combined with other agent(s). The data are being generated quickly and globally. As such, the field of HCC treatment is at a tipping point for potential major advances in the treatment of HCC.

\section{Compliance with ethics guidelines}

Amy Lee and Fa-Chyi Lee declare that they have no conflicts of interest and nothing to declare. This manuscript is a review article and does not involve a research protocol requiring approval by the relevant institutional review board or ethics committee.

Open Access This article is licensed under a Creative Commons Attribution 4.0 International License, which permits use, sharing, adaptation, distribution and reproduction in any medium or format, as long as you give appropriate credit to the original author(s) and the source, provide a link to the Creative Commons licence, and indicate if changes were made.

The images or other third party material in this article are included in the article's Creative Commons licence, unless indicated otherwise in a credit line to the material. If material is not included in the article's Creative Commons licence and your intended use is not permitted by statutory regulation or exceeds the permitted use, you will need to obtain permission directly from the copyright holder.

To view a copy of this licence, visit https://creativecommons.org/ licenses/by/4.0/.

\section{References}

1. Lai CL, Wu PC, Chan GC, Lok AS, Lin HJ. Doxorubicin versus no 
antitumor therapy in inoperable hepatocellular carcinoma. A prospective randomized trial. Cancer 1988; 62(3): 479-483

2. Mok TS, Leung TW, Lee SD, Chao Y, Chan AT, Huang A, Lui MC, Yeo W, Chak K, Johnston A, Johnson P. A multi-centre randomized phase II study of nolatrexed versus doxorubicin in treatment of Chinese patients with advanced hepatocellular carcinoma. Cancer Chemother Pharmacol 1999; 44(4): 307-311

3. Gish RG, Porta C, Lazar L, Ruff P, Feld R, Croitoru A, Feun L, Jeziorski K, Leighton J, Gallo J, Kennealey GT. Phase III randomized controlled trial comparing the survival of patients with unresectable hepatocellular carcinoma treated with nolatrexed or doxorubicin. J Clin Oncol 2007; 25(21): 3069-3075

4. Halm U, Etzrodt G, Schiefke I, Schmidt F, Witzigmann H, Mössner J, Berr F. A phase II study of pegylated liposomal doxorubicin for treatment of advanced hepatocellular carcinoma. Ann Oncol 2000; 11(1): 113-114

5. Schmidinger M, Wenzel C, Locker GJ, Muehlbacher F, Steininger R, Gnant M, Crevenna R, Budinsky AC. Pilot study with pegylated liposomal doxorubicin for advanced or unresectable hepatocellular carcinoma. Br J Cancer 2001; 85(12): 1850-1852

6. Hong RL, Tseng YL. A phase II and pharmacokinetic study of pegylated liposomal doxorubicin in patients with advanced hepatocellular carcinoma. Cancer Chemother Pharmacol 2003; 51 (5): 433-438

7. Wilhelm SM, Carter C, Tang L, Wilkie D, McNabola A, Rong H, Chen C, Zhang X, Vincent P, McHugh M, Cao Y, Shujath J, Gawlak S, Eveleigh D, Rowley B, Liu L, Adnane L, Lynch M, Auclair D, Taylor I, Gedrich R, Voznesensky A, Riedl B, Post LE, Bollag G, Trail PA. BAY 43-9006 exhibits broad spectrum oral antitumor activity and targets the RAF/MEK/ERK pathway and receptor tyrosine kinases involved in tumor progression and angiogenesis. Cancer Res 2004; 64(19): 7099-7109

8. Liu L, Cao Y, Chen C, Zhang X, McNabola A, Wilkie D, Wilhelm S, Lynch M, Carter C. Sorafenib blocks the RAF/MEK/ERK pathway, inhibits tumor angiogenesis, and induces tumor cell apoptosis in hepatocellular carcinoma model PLC/PRF/5. Cancer Res 2006; 66(24): 11851-11858

9. Strumberg D, Richly H, Hilger RA, Schleucher N, Korfee S, Tewes M, Faghih M, Brendel E, Voliotis D, Haase CG, Schwartz B, Awada A, Voigtmann R, Scheulen ME, Seeber S. Phase I clinical and pharmacokinetic study of the Novel Raf kinase and vascular endothelial growth factor receptor inhibitor BAY 43-9006 in patients with advanced refractory solid tumors. J Clin Oncol 2005; 23(5): 965-972

10. Abou-Alfa GK, Schwartz L, Ricci S , Amadori D, Santoro A, Figer A, De Greve J, Douillard JY, Lathia C, Schwartz B, Taylor I, Moscovici M, Saltz LB. Phase II study of sorafenib in patients with advanced hepatocellular carcinoma. J Clin Oncol 2006; 24(26): 4293-4300

11. Llovet JM, Ricci S, Mazzaferro V, Hilgard P, Gane E, Blanc JF, de Oliveira AC, Santoro A, Raoul JL, Forner A, Schwartz M, Porta C, Zeuzem S, Bolondi L, Greten TF, Galle PR, Seitz JF, Borbath I, Häussinger D, Giannaris T, Shan M, Moscovici M, Voliotis D, Bruix J; SHARP Investigators Study Group. Sorafenib in advanced hepatocellular carcinoma. N Engl J Med 2008; 359(4): 378-390

12. Cheng AL, Kang YK, Chen Z, Tsao CJ, Qin S, Kim JS, Luo R, Feng J, Ye S, Yang TS, Xu J, Sun Y, Liang H, Liu J, Wang J, Tak WY, Pan H, Burock K, Zou J, Voliotis D, Guan Z. Efficacy and safety of sorafenib in patients in the Asia-Pacific region with advanced hepatocellular carcinoma: a phase III randomised, double-blind, placebo-controlled trial. Lancet Oncol 2009; 10(1): 25-34

13. Richly H, Henning BF, Kupsch P, Passarge K, Grubert M, Hilger RA, Christensen O, Brendel E, Schwartz B, Ludwig M, Flashar C, Voigtmann R, Scheulen ME, Seeber S, Strumberg D. Results of a Phase I trial of sorafenib (BAY 43-9006) in combination with doxorubicin in patients with refractory solid tumors. Ann Oncol 2006; 17(5): 866-873

14. Richly H, Schultheis B, Adamietz IA, Kupsch P, Grubert M, Hilger RA, Ludwig M, Brendel E, Christensen O, Strumberg D. Combination of sorafenib and doxorubicin in patients with advanced hepatocellular carcinoma: results from a phase I extension trial. Eur J Cancer 2009; 45(4): 579-587

15. Abou-Alfa GK, Niedwieski D, Knox JJ, et al. Phase III randomized study of sorafenib plus doxorubicin versus sorafenib in patients with advanced hepatocellular carcinoma (HCC): CALGB 80802 (Alliance). J Clin Oncol 2016; 34(4 suppl): 192

16. Blivet-Van Eggelpoël MJ, Chettouh H, Fartoux L, Aoudjehane L, Barbu V, Rey C, Priam S, Housset C, Rosmorduc O, DesboisMouthon C. Epidermal growth factor receptor and HER-3 restrict cell response to sorafenib in hepatocellular carcinoma cells. J Hepatol 2012; 57(1): 108-115

17. Zhu AX, Rosmorduc O, Evans TR, Ross PJ, Santoro A, Carrilho FJ, Bruix J, Qin S, Thuluvath PJ, Llovet JM, Leberre MA, Jensen M, Meinhardt G, Kang YK. SEARCH: a phase III, randomized, doubleblind, placebo-controlled trial of sorafenib plus erlotinib in patients with advanced hepatocellular carcinoma. J Clin Oncol 2015; 33(6): 559-566

18. Faivre S, Delbaldo C, Vera K, Robert C, Lozahic S, Lassau N, Bello C, Deprimo S, Brega N, Massimini G, Armand JP, Scigalla P, Raymond E. Safety, pharmacokinetic, and antitumor activity of SU11248, a novel oral multitarget tyrosine kinase inhibitor, in patients with cancer. J Clin Oncol 2006; 24(1): 25-35

19. Cheng AL, Kang YK, Lin DY, Park JW, Kudo M, Qin S, Chung $\mathrm{HC}$, Song X, Xu J, Poggi G, Omata M, Pitman Lowenthal S, Lanzalone S, Yang L, Lechuga MJ, Raymond E. Sunitinib versus sorafenib in advanced hepatocellular cancer: results of a randomized phase III trial. J Clin Oncol 2013; 31(32): 4067-4075

20. Bhide RS, Lombardo LJ, Hunt JT, Cai ZW, Barrish JC, Galbraith S, Jeyaseelan R Sr, Mortillo S, Wautlet BS, Krishnan B, Kukral D, Malone H, Lewin AC, Henley BJ, Fargnoli J. The antiangiogenic activity in xenograft models of brivanib, a dual inhibitor of vascular endothelial growth factor receptor-2 and fibroblast growth factor receptor-1 kinases. Mol Cancer Ther 2010; 9(2): 369-378

21. Johnson PJ, Qin S, Park JW, Poon RT, Raoul JL, Philip PA, Hsu $\mathrm{CH}, \mathrm{Hu} \mathrm{TH}, \mathrm{Heo}$ J, Xu J, Lu L, Chao Y, Boucher E, Han KH, Paik SW, Robles-Aviña J, Kudo M, Yan L, Sobhonslidsuk A, Komov D, Decaens T, Tak WY, Jeng LB, Liu D, Ezzeddine R, Walters I, Cheng AL. Brivanib versus sorafenib as first-line therapy in patients with unresectable, advanced hepatocellular carcinoma: results from the randomized phase III BRISK-FL study. J Clin Oncol 2013; 31 (28): 3517-3524

22. Llovet JM, Decaens T, Raoul JL, Boucher E, Kudo M, Chang C, Kang YK, Assenat E, Lim HY, Boige V, Mathurin P, Fartoux L, Lin DY, Bruix J, Poon RT, Sherman M, Blanc JF, Finn RS, Tak WY, Chao Y, Ezzeddine R, Liu D, Walters I, Park JW. Brivanib in patients with advanced hepatocellular carcinoma who were intoler- 
ant to sorafenib or for whom sorafenib failed: results from the randomized phase III BRISK-PS study. J Clin Oncol 2013; 31(28): 3509-3516

23. Grothey A, Van Cutsem E, Sobrero A, Siena S, Falcone A, Ychou M, Humblet Y, Bouché O, Mineur L, Barone C, Adenis A, Tabernero J, Yoshino T, Lenz HJ, Goldberg RM, Sargent DJ, Cihon F, Cupit L, Wagner A, Laurent D; CORRECT Study Group. Regorafenib monotherapy for previously treated metastatic colorectal cancer (CORRECT): an international, multicentre, randomised, placebo-controlled, phase 3 trial. Lancet 2013; 381(9863): 303-312

24. Goel G. Evolution of regorafenib from bench to bedside in colorectal cancer: is it an attractive option or merely a "me too" drug? Cancer Manag Res 2018; 10: 425-437

25. Bruix J, Qin S, Merle P, Granito A, Huang YH, Bodoky G, Pracht M, Yokosuka O, Rosmorduc O, Breder V, Gerolami R, Masi G, Ross PJ, Song T, Bronowicki JP, Ollivier-Hourmand I, Kudo M, Cheng AL, Llovet JM, Finn RS, LeBerre MA, Baumhauer A, Meinhardt G, Han G; RESORCE Investigators. Regorafenib for patients with hepatocellular carcinoma who progressed on sorafenib treatment (RESORCE): a randomised, double-blind, placebocontrolled, phase 3 trial. Lancet 2017; 389(10064): 56-66

26. Matsui J, Yamamoto Y, Funahashi Y, Tsuruoka A, Watanabe T, Wakabayashi T, Uenaka T, Asada M. E7080, a novel inhibitor that targets multiple kinases, has potent antitumor activities against stem cell factor producing human small cell lung cancer H146, based on angiogenesis inhibition. Int J Cancer 2008; 122(3): 664-671

27. Ikeda K, Kudo M, Kawazoe S, Osaki Y, Ikeda M, Okusaka T, Tamai T, Suzuki T, Hisai T, Hayato S, Okita K, Kumada H. Phase 2 study of lenvatinib in patients with advanced hepatocellular carcinoma. $\mathrm{J}$ Gastroenterol 2017; 52(4): 512-519

28. Kudo M, Finn RS, Qin S, Han KH, Ikeda K, Piscaglia F, Baron A, Park JW, Han G, Jassem J, Blanc JF, Vogel A, Komov D, Evans TRJ, Lopez C, Dutcus C, Guo M, Saito K, Kraljevic S, Tamai T, Ren $M$, Cheng AL. Lenvatinib versus sorafenib in first-line treatment of patients with unresectable hepatocellular carcinoma: a randomised phase 3 non-inferiority trial. Lancet 2018; 391(10126): $1163-1173$

29. Yakes FM, Chen J, Tan J, Yamaguchi K, Shi Y, Yu P, Qian F, Chu F, Bentzien F, Cancilla B, Orf J, You A, Laird AD, Engst S, Lee L, Lesch J, Chou YC, Joly AH. Cabozantinib (XL184), a novel MET and VEGFR2 inhibitor, simultaneously suppresses metastasis, angiogenesis, and tumor growth. Mol Cancer Ther 2011; 10(12): 2298-2308

30. Kelley RK, Verslype C, Cohn AL, Yang TS, Su WC, Burris H, Braiteh F, Vogelzang N, Spira A, Foster P, Lee Y, Van Cutsem E. Cabozantinib in hepatocellular carcinoma: results of a phase 2 placebo-controlled randomized discontinuation study. Ann Oncol 2017; 28(3): 528-534

31. Abou-Alfa GK, Meyer T, Cheng AL, El-Khoueiry AB, Rimassa L, Ryoo BY, Cicin I, Merle P, Chen Y, Park JW, Blanc JF, Bolondi L, Klümpen HJ, Chan SL, Zagonel V, Pressiani T, Ryu MH, Venook AP, Hessel C, Borgman-Hagey AE, Schwab G, Kelley RK. Cabozantinib in patients with advanced and progressing hepatocellular carcinoma. N Engl J Med 2018; 379(1): 54-63

32. Ellis LM. Mechanisms of action of bevacizumab as a component of therapy for metastatic colorectal cancer. Semin Oncol 2006; 33(5 Suppl 10): S1-S7
33. Fang P, Hu JH, Cheng ZG, Liu ZF, Wang JL, Jiao SC. Efficacy and safety of bevacizumab for the treatment of advanced hepatocellular carcinoma: a systematic review of phase II trials. PLoS One 2012; 7 (12): e49717

34. Hubbard JM, Mahoney MR, Loui WS, Roberts LR, Smyrk TC, Gatalica Z, Borad M, Kumar S, Alberts SR. Phase I/II random-ized trial of sorafenib and bevacizumab as first-line therapy in patients with locally advanced or metastatic hepatocellular carcinoma: North Central Cancer Treatment Group trial N0745 (Alliance). Target Oncol 2017; 12(2): 201-209

35. Torimura $\mathrm{T}$, Iwamoto $\mathrm{H}, \mathrm{Nakamura} \mathrm{T}$, Abe M, Ikezono $\mathrm{Y}$, Wada F, Sakaue T, Masuda H, Hashimoto O, Koga H, Ueno T, Yano H. Antiangiogenic and antitumor activities of aflibercept, a soluble VEGF receptor-1 and -2 , in a mouse model of hepatocellular carcinoma. Neoplasia 2016; 18(7): 413-424

36. Sprat;om JL, Cohen RB, Eadens M, et al. Phase I pharmacologic and biologic study of ramucirumab (IMC-1121B), a fully human immunoglobulin G1 monoclonal antibody targeting the vascular endothelial growth factor receptor-2. J Clin Oncol 2010; 28: 780787

37. Zhu AX, Park JO, Ryoo BY, Yen CJ, Poon R, Pastorelli D, Blanc JF, Chung HC, Baron AD, Pfiffer TE, Okusaka T, Kubackova K, Trojan J, Sastre J, Chau I, Chang SC, Abada PB, Yang L, Schwartz JD, Kudo M; REACH Trial Investigators. Ramucirumab versus placebo as second-line treatment in patients with advanced hepatocellular carcinoma following first-line therapy with sorafenib (REACH): a randomised, double-blind, multicentre, phase 3 trial. Lancet Oncol 2015; 16(7): 859-870

38. Zhu AX, Kang YK, Yen CJ, Finn RS, Galle PR, Llovet JM, Assenat E, Brandi G, Pracht M, Lim HY, Rau KM, Motomura K, Ohno I, Merle P, Daniele B, Shin DB, Gerken G, Borg C, Hiriart JB, Okusaka T, Morimoto M, Hsu Y, Abada PB, Kudo M; REACH-2 study investigators. Ramucirumab after sorafenib in patients with advanced hepatocellular carcinoma and increased $\alpha$-fetoprotein concentrations (REACH-2): a randomised, double-blind, placebocontrolled, phase 3 trial. Lancet Oncol 2019; 20(2): 282-296

39. Llovet JM, Montal R, Sia D, Finn RS. Molecular therapies and precision medicine for hepatocellular carcinoma. Nat Rev Clin Oncol 2018; 15(10): 599-616

40. Santoro A, Rimassa L, Borbath I, Daniele B, Salvagni S, Van Laethem JL, Van Vlierberghe H, Trojan J, Kolligs FT, Weiss A, Miles S, Gasbarrini A, Lencioni M, Cicalese L, Sherman M, Gridelli C, Buggisch P, Gerken G, Schmid RM, Boni C, Personeni N, Hassoun Z, Abbadessa G, Schwartz B, Von Roemeling R, Lamar ME, Chen Y, Porta C. Tivantinib for second-line treatment of advanced hepatocellular carcinoma: a randomised, placebo-controlled phase 2 study. Lancet Oncol 2013; 14(1): 55-63

41. Rimassa L, Assenat E, Peck-Radosavljevic M, Pracht M, Zagonel V, Mathurin P, Rota Caremoli E, Porta C, Daniele B, Bolondi L, Mazzaferro V, Harris W, Damjanov N, Pastorelli D, Reig M, Knox J, Negri F, Trojan J, López López C, Personeni N, Decaens T, Dupuy M, Sieghart W, Abbadessa G, Schwartz B, Lamar M, Goldberg T, Shuster D, Santoro A, Bruix J. Tivantinib for secondline treatment of MET-high, advanced hepatocellular carcinoma (METIV-HCC): a final analysis of a phase 3, randomised, placebocontrolled study. Lancet Oncol 2018; 19(5): 682-693

42. Hoshida Y, Nijman SM, Kobayashi M, Chan JA, Brunet JP, Chiang DY, Villanueva A, Newell P, Ikeda K, Hashimoto M, Watanabe G, 
Gabriel S, Friedman SL, Kumada H, Llovet JM, Golub TR. Integrative transcriptome analysis reveals common molecular subclasses of human hepatocellular carcinoma. Cancer Res 2009; 69(18): 7385-7392

43. Boyault S, Rickman DS, de Reyniès A, Balabaud C, Rebouissou S, Jeannot E, Hérault A, Saric J, Belghiti J, Franco D, Bioulac-Sage P, Laurent-Puig P, Zucman-Rossi J. Transcriptome classification of HCC is related to gene alterations and to new therapeutic targets. Hepatology 2007; 45(1): 42-52

44. El-Khoueiry AB, Sangro B, Yau T, Crocenzi TS, Kudo M, Hsu C, Kim TY, Choo SP, Trojan J, Welling TH 3rd, Meyer T, Kang YK, Yeo W, Chopra A, Anderson J, Dela Cruz C, Lang L, Neely J, Tang H, Dastani HB, Melero I. Nivolumab in patients with advanced hepatocellular carcinoma (CheckMate 040): an open-label, noncomparative, phase 1/2 dose escalation and expansion trial. Lancet 2017; 389(10088): 2492-2502

45. Zhu AX, Finn RS, Edeline J, Cattan S, Ogasawara S, Palmer D, Verslype C, Zagonel V, Fartoux L, Vogel A, Sarker D, Verset G, Chan SL, Knox J, Daniele B, Webber AL, Ebbinghaus SW, Ma J, Siegel AB, Cheng AL, Kudo M; KEYNOTE-224 investigators. Pembrolizumab in patients with advanced hepatocellular carcinoma previously treated with sorafenib (KEYNOTE-224): a non-randomised, open-label phase 2 trial. Lancet Oncol 2018; 19(7): 940-952

46. Finn RS, Ryoo BY, Merle P, et al. Results of Keynote-240: phase 3 study of pembrolizumab (Pembro) vs best supportive care (BSC) for second line therapy in advanced hepatocellular carcinoma (HCC). J Clin Oncol 2019; 37 (suppl) : 4004

47. Lee K, HSU C, Lee MS, et al. Atezolizumab + Bevacizumab in hepatocellular carcinoma (HCC): safety and clinical activity results from a Phase 1b study. Ann Oncol 2018; 29 (suppl_9): mdy432

48. Xu J, Zhang Y, Jia R, Yue C, Chang L, Liu R, Zhang G, Zhao C, Zhang Y, Chen C, Wang Y, Yi X, Hu Z, Zou J, Wang Q. Anti-PD-1 antibody SHR-1210 combined with Apatinib for advanced hepatocellular carcinoma, gastric, or esophagogastric junction cancer: an open-label, dose escalation and expansion study. Clin Cancer Res 2019; 25(2): 515-523

49. Yau TC, Tang V, Chan J, et al. Outcomes of tyrosine kinase inhibitors (TKI) after immunotherapy in unresectable or advanced hepatocellular carcinoma (HCC) patients. J Clin Oncol 2019;39(4) suppl.361

50. Liu X, Qin S. Immune Checkpoint inhibitors in hepatocellular carcinoma: opportunities and challenges. Oncologist 2019; 24 (Suppl 1): S3-S10

51. Abdel-Wahab N, Safa H, Abudayyeh A, Johnson DH, Trinh VA, Zobniw CM, Lin H, Wong MK, Abdelrahim M, Gaber AO, SuarezAlmazor ME, Diab A. Checkpoint inhibitors therapy for cancer in solid organ transplantation recipients: an institutional experience and a systemic review of the literature. J Immunother Cancer 2019; 7(1): 106

52. Munker S, De Toni EN. Use of checkpoint inhibitors in liver transplant recipients. United European Gastroenterol J 2018; 6(7): 970-973

53. Ho CM, Chen HL, Hu RH, Lee PH. Harnessing immunotherapy for liver recipients with hepatocellular carcinoma: a review from a transplant oncology perspective. Ther Adv Med Oncol 2019; 11: 1758835919843463
54. Qin S, Bai Y, Lim HY, Thongprasert S, Chao Y, Fan J, Yang TS, Bhudhisawasdi V, Kang WK, Zhou Y, Lee JH, Sun Y. Randomized, multicenter, open-label study of oxaliplatin plus fluorouracil/ leucovorin versus doxorubicin as palliative chemotherapy in patients with advanced hepatocellular carcinoma from Asia. J Clin Oncol 2013; 31(28): 3501-3508

55. Lee DW, Lee KH, Kim HJ, Kim TY, Kim JS, Han SW, Oh DY, Kim JH, Im SA, Kim TY. A phase II trial of S-1 and oxaliplatin in patients with advanced hepatocellular carcinoma. BMC Cancer 2018; 18(1): 252

56. Reig M, Mariño Z, Perelló C, Iñarrairaegui M, Ribeiro A, Lens $S$, Díaz A, Vilana R, Darnell A, Varela M, Sangro B, Calleja JL, Forns $\mathrm{X}$, Bruix J. Unexpected high rate of early tumor recurrence in patients with HCV-related HCC undergoing interferon-free therapy. J Hepatol 2016; 65(4): 719-726

57. Conti F, Buonfiglioli F, Scuteri A, Crespi C, Bolondi L, Caraceni P, Foschi FG, Lenzi M, Mazzella G, Verucchi G, Andreone P, Brillanti $\mathrm{S}$. Early occurrence and recurrence of hepatocellular carcinoma in HCV-related cirrhosis treated with direct-acting antivirals. J Hepatol 2016; 65(4): 727-733

58. Nagata H, Nakagawa M, Asahina Y, Sato A, Asano Y, Tsunoda T, Miyoshi M, Kaneko S, Otani S, Kawai-Kitahata F, Murakawa M, Nitta S, Itsui Y, Azuma S, Kakinuma S, Nouchi T, Sakai H, Tomita M, Watanabe M; Ochanomizu Liver Conference Study Group. Effect of interferon-based and-free therapy on early occurrence and recurrence of hepatocellular carcinoma in chronic hepatitis C. J Hepatol 2017; 67(5): 933-939

59. Singal AG, Rich NE, Mehta N, Branch A, Pillai A, Hoteit M, Volk M, Odewole M, Scaglione S, Guy J, Said A, Feld JJ, John BV, Frenette C, Mantry P, Rangnekar AS, Oloruntoba O, Leise M, Jou JH, Bhamidimarri KR, Kulik L, Tran T, Samant H, Dhanasekaran R, Duarte-Rojo A, Salgia R, Eswaran S, Jalal P, Flores A, Satapathy SK, Wong R, Huang A, Misra S, Schwartz M, Mitrani R, Nakka S, Noureddine W, Ho C, Konjeti VR, Dao A, Nelson K, Delarosa K, Rahim U, Mavuram M, Xie JJ, Murphy CC, Parikh ND. Directacting antiviral therapy no associated with recurrence of hepatocellular carcinoma in a multicenter North American cohort study. Gastroenterology 2019; 156(6): 1683-1692.e1

60. Guarino M, Sessa A, Cossiga V, Morando F, Caporaso N, Morisco F; Special Interest Group on "Hepatocellular carcinoma and new anti-HCV therapies" of the Italian Association for the Study of the Liver. Direct-acting antivirals and hepatocellular carcinoma in chronic hepatitis C: a few lights and many shadows. World J Gastroenterol 2018; 24(24): 2582-2595

61. Guarino M, Viganò L, Ponziani FR, Giannini EG, Lai Q, Morisco F; Special Interest Group on Hepatocellular carcinoma and new antiHCV therapies" of the Italian Association for the Study of the Liver. Recurrence of hepatocellular carcinoma after direct acting antiviral treatment for hepatitis $\mathrm{C}$ virus infection: literature review and risk analysis. Dig Liver Dis 2018; 50(11): 1105-1114

62. Zhang YQ, Guo JS. Antiviral therapies for hepatitis B virus-related hepatocellular carcinoma. World J Gastroenterol 2015; 21(13): 3860-3866

63. Pazgan-Simon M, Simon KA, Jarowicz E, Rotter K, SzymanekPasternak A, Zuwała-Jagiełło J. Hepatitis B virus treatment in hepatocellular carcinoma patients prolongs survival and reduces the risk of cancer recurrence. Clin Exp Hepatol 2018; 4(3): 210-216 